\title{
Prioritization of Loita Maasai medicinal plants for conservation
}

\author{
Jedidah Nankaya ${ }^{1,2} \cdot$ Nathan Gichuki $^{1} \cdot$ Catherine Lukhoba ${ }^{1} \cdot$ Henrik Balslev $^{3}$ (D)
}

Received: 22 September 2019 / Revised: 6 January 2021 / Accepted: 10 January 2021 /

Published online: 28 January 2021

(C) The Author(s) 2021

\begin{abstract}
Medicinal plants provide biodiversity-based ecosystem services including health to many communities around the world and therefore, medicinal plant conservation is vital for sustainability. Here, we identify medicinal plants to be prioritized for conservation among the Loita Maasai who are pastoralists in the extensive East African savannah. A botanical survey and interviews were conducted with 91 villagers; 49 women and 42 men drawn randomly from 45 households. A conservation priority list was developed based on (1) the plant part harvested, (2) the species use value, and (3) its availability. These criteria were evaluated independently for each species on a scale from 1 to 4 and their sum was taken as the species' score. The score for the species varied from 5 to 9. The higher the total score value of a species, the higher its priority for conservation. Among the medicinal plants used by the community, 20 species were shortlisted as regularly used and found around the village. Out of these, 12 species that had scores above seven were considered top priority for conservation. A total of 1179 use reports were obtained from the villagers and they were placed in 12 use categories as defined in the International Classification of Primary Care system. Plants used to treat digestive system disorder had most use reports (21\%), followed by the muscular skeletal disorders (20\%). This study identified 12 medicinal plant species that should be given conservation priority to make them available for the wellbeing of the people and sustainability of ecosystem products and services. An assessment of medicinal plants species using standard ecological methods is recommended.
\end{abstract}

Keywords Medicinal plants conservation · Ethnomedicinal uses $\cdot$ Prioritization $\cdot$ Loita Kenya $\cdot$ Maasai

Communicated by Danna J Leaman.

This article belongs to the Topical Collection: Biodiversity exploitation and use.

Henrik Balslev

henrik.balslev@biology.au.dk

Extended author information available on the last page of the article 


\section{Introduction}

Ongoing environmental degradation, climate change, urbanization, habitat destruction, etc. (Anyinam 1995; Voeks and Leony 2004), threaten the future availability of medicinal plants most of which are collected from the wild. Further, the demand for medicinal plant species has increased as people prefer to use natural medicinal plants for their health needs, resulting in heavy exploitation of species with medicinal value. The high demand is likely to have negative impact on the natural stock. In India, approximately $90 \%$ of the species used in the manufacturing of herbal drugs is obtained from the wild. Because of the high demand, some of these species are subjected to destructive harvesting practices resulting in unsustainable exploitation (Dhar et al. 2000; Singh and Dey 2005).

In developing countries such as Kenya, approximately $80 \%$ of the rural population relies on medicinal plants for medication (WHO 2002). The reliance on medicinal plants for treatment of a variety of diseases has a long history of being a cheap and effective alternative to industrially produced medicines, and therefore, medicinal plants provide an important ecosystem service to many cultures globally (Padulosi et al. 2002). The continuous use of medicinal plants around the world, has contributed to an accumulation of a wealth of local knowledge (Srithi et al. 2009) which has been used to inform conservation measures for protection and management of natural biodiversitybased resources (Berkes et al. 2000; Mackinson and Nottestad 1998; Huntington 2000).

The high demand for medicinal plants globally has resulted in increased attention towards conservation (Franz 1993; Gupta et al. 1998). The use of both local ethnomedicinal knowledge and scientific insights can aid in development of local conservation strategies that are sustainable and socially acceptable to the local communities such as the Maasai.

Ethnobotany provides important background for natural resource conservation and has been used in the identification of medicinal species for conservation (Rausser and Small 2000). The interest in incorporating local ecological knowledge into conservation is highlighted in Article 8-J of the Convention of Biological Diversity, and further supported by the Millennium Ecosystem Assessment (2005).

Local people possess important ecological knowledge of the available resources in their environments, information which can be used to monitor biodiversity change, and provide local ecosystem-based solutions.

On the other hand, scientific approaches to conservation involving both in situ and ex situ strategies have been applied in conservation of threatened species (Etkin 1998). The ex situ conservation entails conservation of genetic materials away from their natural environments while the in situ approach involves conserving wild species within their natural environments (Etkin 1998). Both approaches have been used in medicinal plant conservation worldwide. For example, in Brazil, ex situ conservation has been used to conserve both native and exotic species. The seeds of the threatened species are stored in seedbanks, and some species such as aloe (Aloe spp.) are cultivated in home gardens (Vieira 1999). Similarly, in Ethiopia, medicinal plants that are in high demand are cultivated in home gardens (Zemede 2001). In Kenya, both ex situ and in situ conservation strategies have been used for conservation. Protected areas, such as the Maasai Mara Game Reserve, provide in situ conservation of a variety of indigenous plant resources while the botanical gardens, such as Maasai Mara University and Jomo Kenyatta University, provide ex situ conservation of plant species rescued from the wild. 
Regardless of the conservation approach chosen, the involvement of the local people in planning and decision making is crucial for success to be achieved (Berkes et al. 2000; McCabe et al. 1992). The local communities are able to monitor changes in biodiversity, information which can be used to inform conservation agendas. For example, in Kenya, the conservancies adjacent to Maasai Mara Game Reserve, have the responsibility of conserving natural vegetation. In Loita, the council of elders is entrusted with management of the Naimina Enkiyio forest on behalf of the Loita Maasai. In this study, we use local knowledge of the community to highlight species that should be given conservation priority due to high demand.

It is important to identify species that are in high demand prior to implementing conservation measures (Figueiredo and Grelle 2009). A number of factors should be considered when identifying the species to be given conservation priority; the use value of a species, the plant parts that are harvested, and the availability of the species (Kala et al. 2004). The use value is a common measure employed to determine the importance of a species (Phillips and Gentry 1993). Plant species that are easy to find are often used to treat more than one disorder, and as a result, they have a higher use value (Martin 2010; Lucena et al. 2007). Different parts of medicinal plants, such as roots, stems, leaves, and fruits, are used for treatments (Huang et al. 2002; Hamilton 2004). Harvesting of different parts of a plant has different impacts on the survival of the plant's population. The plant part used for extraction of medicines therefore has conservation implications for the species, especially for the ones with high use value. The use of roots or the whole plant for treatments could have a major impact on the population of a medicinal plant as compared with the use of the leaves (Giday et al. 2003). Destructive harvesting practices may lead to local extinction of species including such ones that are perceived as abundant (Chi et al. 2017; Kunwar et al. 2015; Ghimire et al. 2005).

Previous studies of medicinal plants used by the Loita Maasai (Nankaya et al. 2019; Maundu et al. 2001), have not considered conservation aspects of the plant populations, including which species should be given conservation priority. Nevertheless, local communities play an important role in community-based conservation of local natural resources (Berkes et al. 2000; McCabe et al. 1992). Our study therefore involved local community members for identification of medicinal plants that should be given conservation priority.

In view of the high reliance on medicinal plants among the Maasai, it is important to identify medicinal species that are highly consumed in Loita for conservation prioritization. The specific objective of this study was to determine which species of medicinal plants should be given priority for conservation, based on use value, plant part harvested and species availability. In this context, we asked the following questions; which medicinal plants should be prioritized for conservation? To which use categories do the plants belong?

This study may contribute to the protection and conservation of lifesaving medicines and ecosystem health.

\section{Methodology}

\section{The Maasai of Kenya}

The Maasai are pastoralists who speak the Maa language and their homeland covers parts of Kenya and Tanzania (Fig. 1) (Galaty 1982). Livestock production is their 

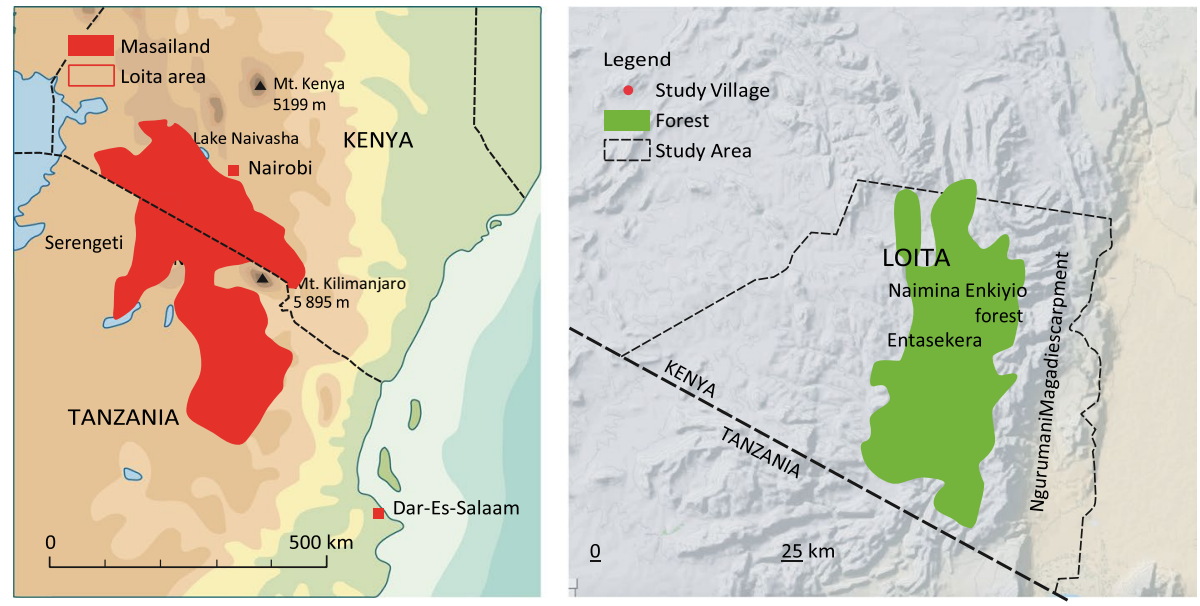

Fig. 1 Map of Maasailand stretching across southern Kenya and northern Tanzania with indication of the placement of the study area in Loita

most important livelihood activity and the main source of wealth (Muchiru et al. 2009; Hughes 2006). Traditionally, the Maasai people move from one place to another in search of fresh pasture and water for their livestock. However, due to the ongoing climate change and land degradation, the settlement pattern has changed over the past decades from temporary to a semi-permanent settlement. This implies that the natural resources, including medicinal plants, could experience unsustainable exploitation in the future (Seno and Shaw 2002; Okello 2005).

The Maasai rely heavily on their natural resources such as water, medicinal plants and pasture for their livestock. As a result, over time, they have accumulated a wealth of knowledge about their local environment (Nankaya et al. 2019; Miaron 2003).

The Loita Maasai who are the focus of this study live in Narok county in Kenya and they have maintained their traditions and cultural practices to date. Their location far away from towns and major health facilities has contributed to their maintenance of traditional practice including the use of medicinal plants (Nankaya et al. 2019). However, like many other pastoralists in Kenya, the Loita Maasai have in the recent past experienced climate change and long spells of droughts leading to loss of livestock which is the Maasai's main source of wealth. As a result, the Loita Maasai have diversified their sources of livelihood to include farming alongside their livestock production so they can now be considered agro-pastoralist. The Loita Maasai are the custodians of their natural resources, including the Naimina Enkiyio forest which is their main source of medicinal plants (Nankaya et al. 2019), water, firewood, and it is home to a variety of wildlife species, such as elephants, buffalos, wildebeests and zebras. The forest is an important corridor for elephants and other animals that migrate to and from the Maasai Mara Game Reserve in search of water and pasture. However, due to the ongoing land use changes from pastoralism to crop cultivation and increased settlements in rangelands and in the forest (Fig. 2), the natural resources including medicinal plants could be facing serious threats. 


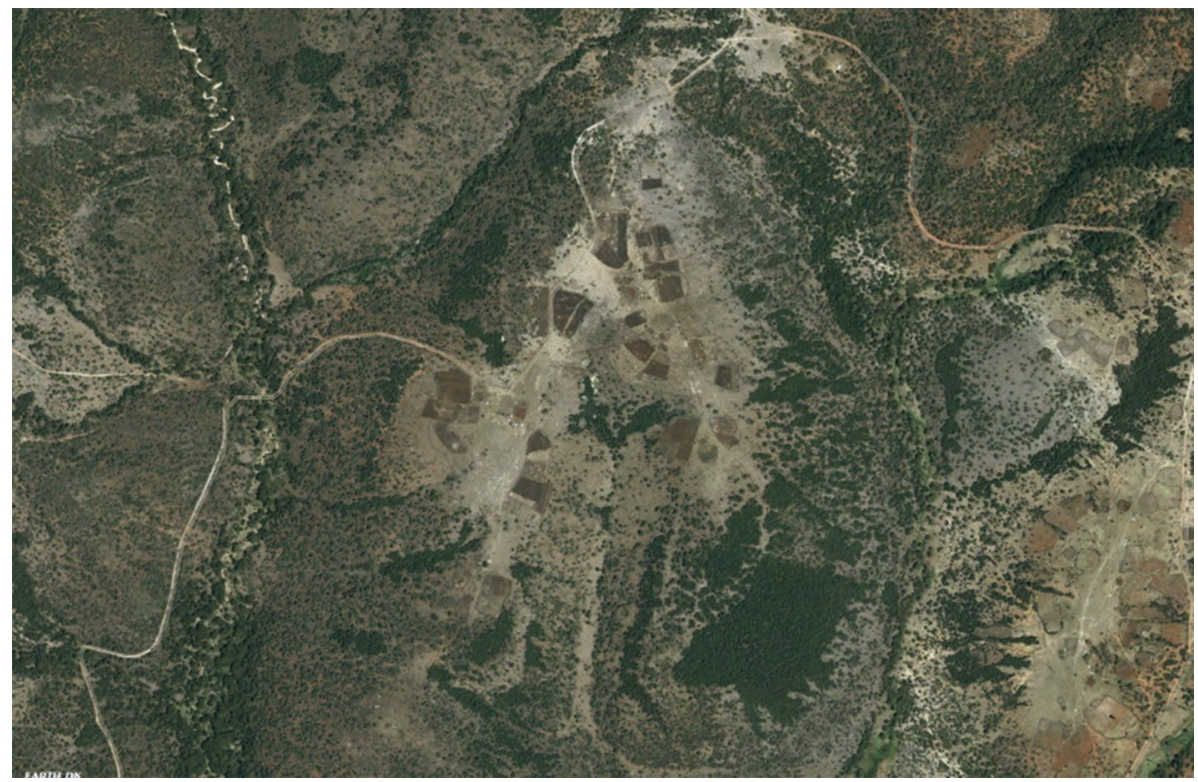

Fig. 2 Satellite image of settlements in the Loita area showing the unpaved dry-season access roads, the settlement surrounded by an open area where the vegetation has been overgrazed (light brown) and several cultivated land parcels (dark brown, straight sides), all embedded in a matrix of dry bush land with scattered shrubs. Areas with denser vegetation can be seen along the stream valleys. Source: Google earth 2019

\section{Study area}

The study was conducted in Entasekera village in Loita, located in southern Kenya (Fig. 1). Entasekera was the most suitable village for the study because of its proximity to the forest and most of the regularly used medicinal plants are found in this village. The Loita sub-county covers $1676 \mathrm{~km}^{2}$ and is home to 25,000 Iloitai, which is the name the people use for themselves. Loita borders the Ngurumani-Magadi escarpment to the east, the United Republic of Tanzania to the south and the Maasai Mara Game Reserve to west. The Naimina Enkiyio forest, which covers some $300 \mathrm{~km}^{2}$ is owned and managed by the Iloitai under traditional laws. The forest is a source of medicinal plants and it is an important wildlife corridor for elephants and other animals that migrate from the famous Maasai Mara Game Reserve to the Loita forest during the dry season for enhanced feeding opportunities. The natural vegetation in Loita includes grassland, wooded grassland, thickets, bush land, dry upland forest, and disturbed forest edges (Fig. 2) (Maundu et al. 2001). The climate is predominantly semi-arid with a mean annual rainfall of 600-2000 mm and temperatures that range from 17 to $20^{\circ} \mathrm{C}$ in the wooded and forested areas and $20-22{ }^{\circ} \mathrm{C}$ in the open rangelands. There are few health facilities with only one in Entasekera that is owned by the Government of Kenya and managed by Narok County Government.

\section{Data collection}

Field work was conducted from July to October, 2018. 
The optimum foraging theory suggests that the distance to resources determines the site for collection (Pyke 1984). As advocated by Soldati and Albuquerque (2012), resources such as medicinal plants which are found closer to the people experience more collection as compared with those far away. In our case, we chose to concentrate on medicinal plants which are found around and within the Entasekera village for conservation prioritization as they are likely to experience collection pressure.

The botanical survey involved the compilation of an inventory of medicinal plants found around the village of which the most common 20 species were subsequently used in the interviews. The compilation of the inventory involved walks within and around the village with three local medicinal plant experts. Local names were noted and vouchers of all medicinal plants around the village were collected in duplicate. One batch was shown to the informants - one specimen at a time - and in the same order. The duplicate set of the voucher specimens was preserved and identified to its scientific name by a taxonomist, and deposited for curation at the University of Nairobi Herbarium (NAI).

The botanical survey was followed by ethnobotanical household interviews involving 91 informants (49 women and 42 men). The 45 households were chosen randomly depending on informant's availability during the study period. The interview questions included information on social demographic traits of the informants, including name, age, and gender. Each informant was shown a fresh sample of a medicinal plant one at a time, and asked if they knew the plant. If they said yes, they were asked for its vernacular name, the human health conditions that the plant was used to treat, as well as the plant part used. We then asked for information on the availability status of each of the 20 species. The informants were asked to give their perceptions of the availability of each species as either abundant and very easy to find, common but becoming less abundant, rare and needing some effort to find, very rare and needing special knowledge to find within and around the village.

\section{Data analysis}

A database was created and data was analyzed in Microsoft office excel spreadsheet. Descriptive statistics was employed to analyze data. Each plant was identified by its local name and its scientific name following the plant list (2013) website (www.theplantlist.org). Medicinal plants are used to treat many disorders which are classified in different systems such as the WHO's international classification (WHO 1987,2017), Cook's categories for economically important plants (Cook 1995), and the international classification of primary care (ICPC) (WONCA 2005). The ICPC classification system is based on an individual's perception of a health problem, and is widely used internationally (WONCA 2005; Staub et al. 2015). We chose to work with the International Classification of Primary Care classification system because the disease categories are informed by the patient's reported symptoms, which makes it possible to classify reported illnesses originating from data obtained through interviews. Each use report was assigned to a use category according to the International Classification of Primary Care. The number of use reports of each species were calculated to determine the use value of a species.

\section{Prioritization approach}

The conservation prioritization was based on a summed score for plant part used, versatility, and availability of the species. Versatility (use value) of a species is the number of ailments that are treated with a particular species. The availability of a species is the 
informant's perception of abundance and efforts needed to find the species (Table 1). The higher the score value of a species, the higher its priority for conservation. Species with a total score of seven and above were considered as top priority for conservation while species with a score of less than seven were considered of secondary priority.

\section{Results}

A total of 20 medicinal plant species were collected at Entasekera in Loita during walks with traditional experts. The plant specimens collected were used to conduct interviews on plant uses with 91 informants. A total of 1179 use reports were obtained from the local villagers and were placed in 12 use categories as defined in the International Classification of Primary Care (ICPC) system. Number of use reports and plant parts harvested for the 12 health disorders and ailments are shown in Table 2.

\section{Priority list for conservation}

The summed score for the species varied from 5 to 9 (Table 3). Out of the 20 species inventoried, 12 were classified in the top priority for conservation with a summed score of seven or above. Myrsine africana was the most important species and it was used in the treatment of sixteen ailments.

Following the WHO's International Classification of Primary Care (ICPC) and the 1179 use reports, we identified 12 broad disease categories (Table 2), as explained below.

\section{Digestive system disorders}

This category had the highest number $(247,21 \%)$ of use reports, and these ailments were treated using 19 of the 20 inventoried species. Illnesses such as a stomach ache, vomiting, and diarrhea dominated in the category and bark and roots were commonly used for treatment.

Table 1 Criteria used for prioritization of medicinal plants in Loita

\begin{tabular}{llc}
\hline Criteria & Sub category & Score \\
\hline Plant part used & Fruits and leaves & 1 \\
& Bark & 2 \\
& Stems and branches & 3 \\
Versatility & Roots & 4 \\
& Species used in 1-5 ailments & 1 \\
& Species used in 6-10 ailments & 2 \\
Availability & Species used in 11-15 ailments & 3 \\
& Species used in >16 ailments & 4 \\
& Abundant and very easy to find & 1 \\
& Common but becoming less abundant & 2 \\
& Rare and needing some effort to find & 3 \\
& Very rare and needing special knowledge to find & 4 \\
\hline
\end{tabular}




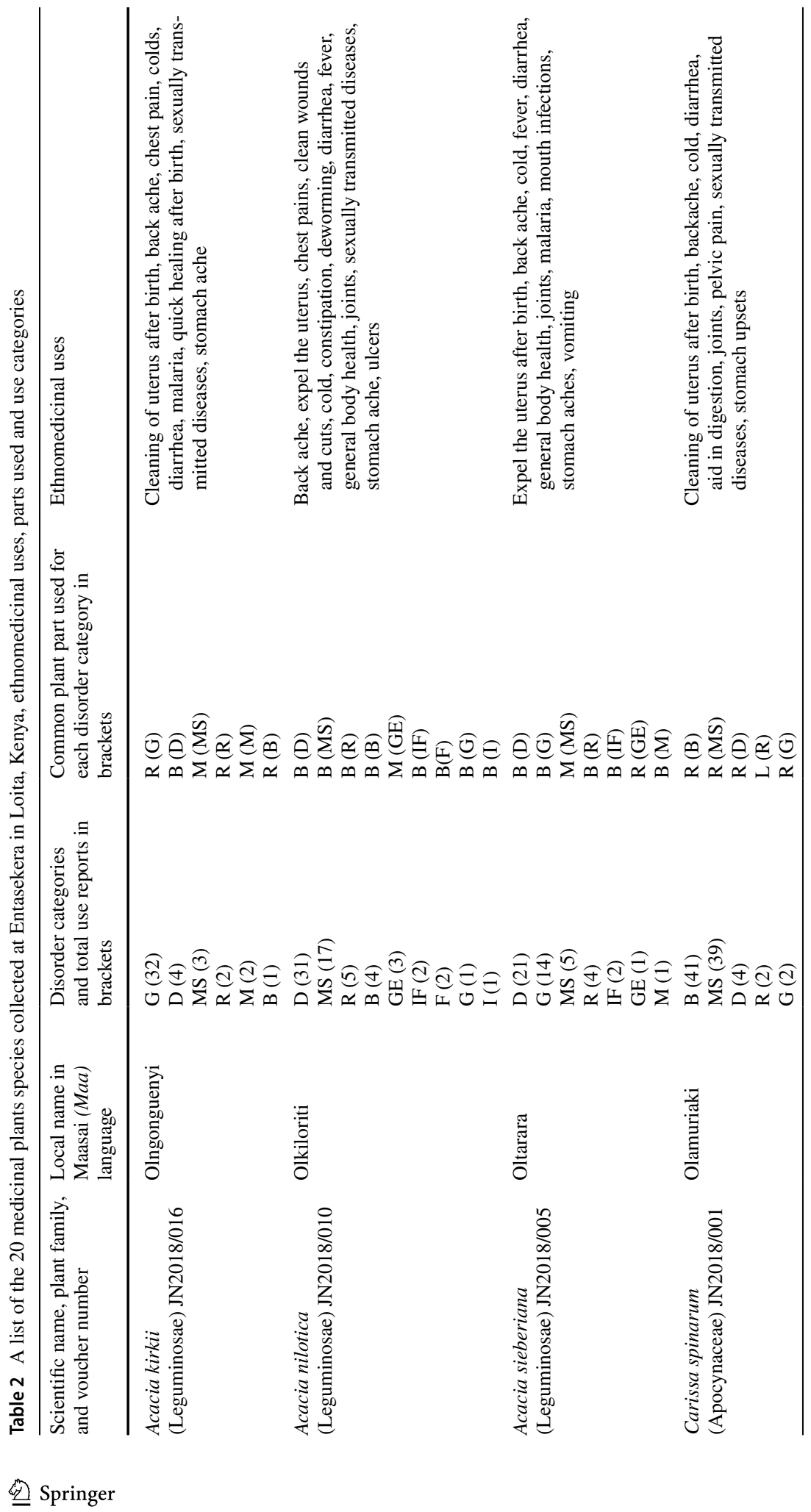




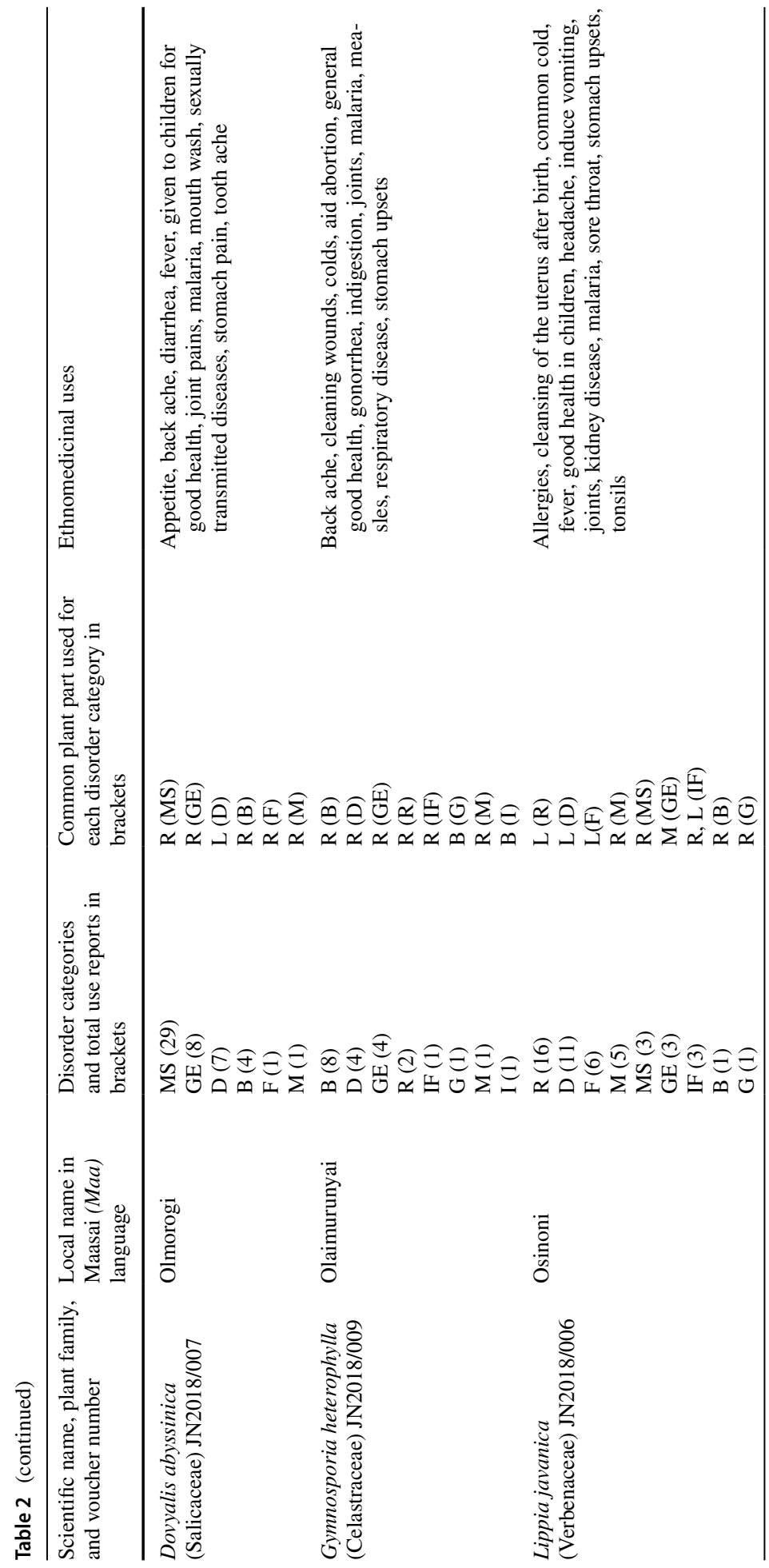




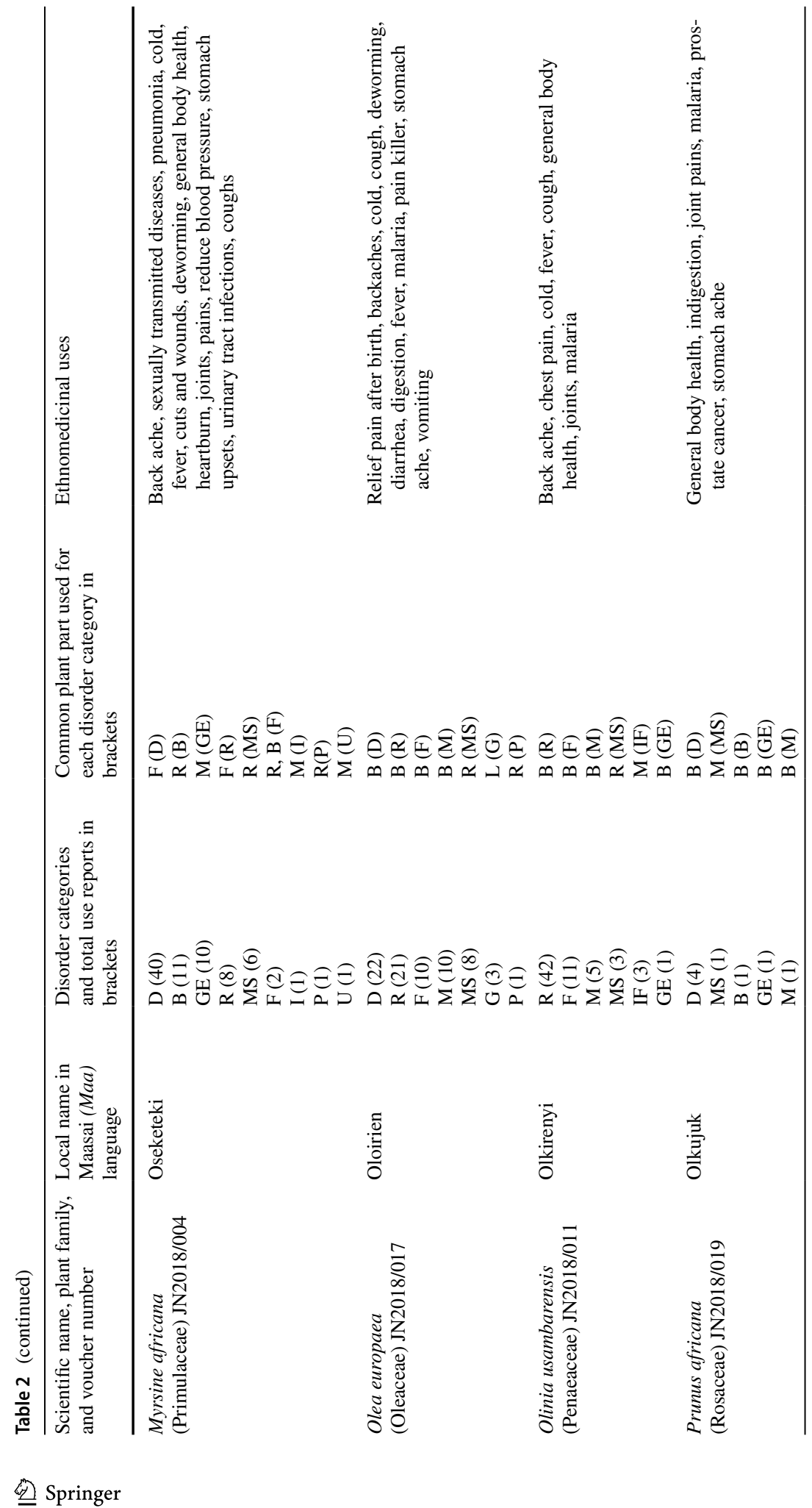




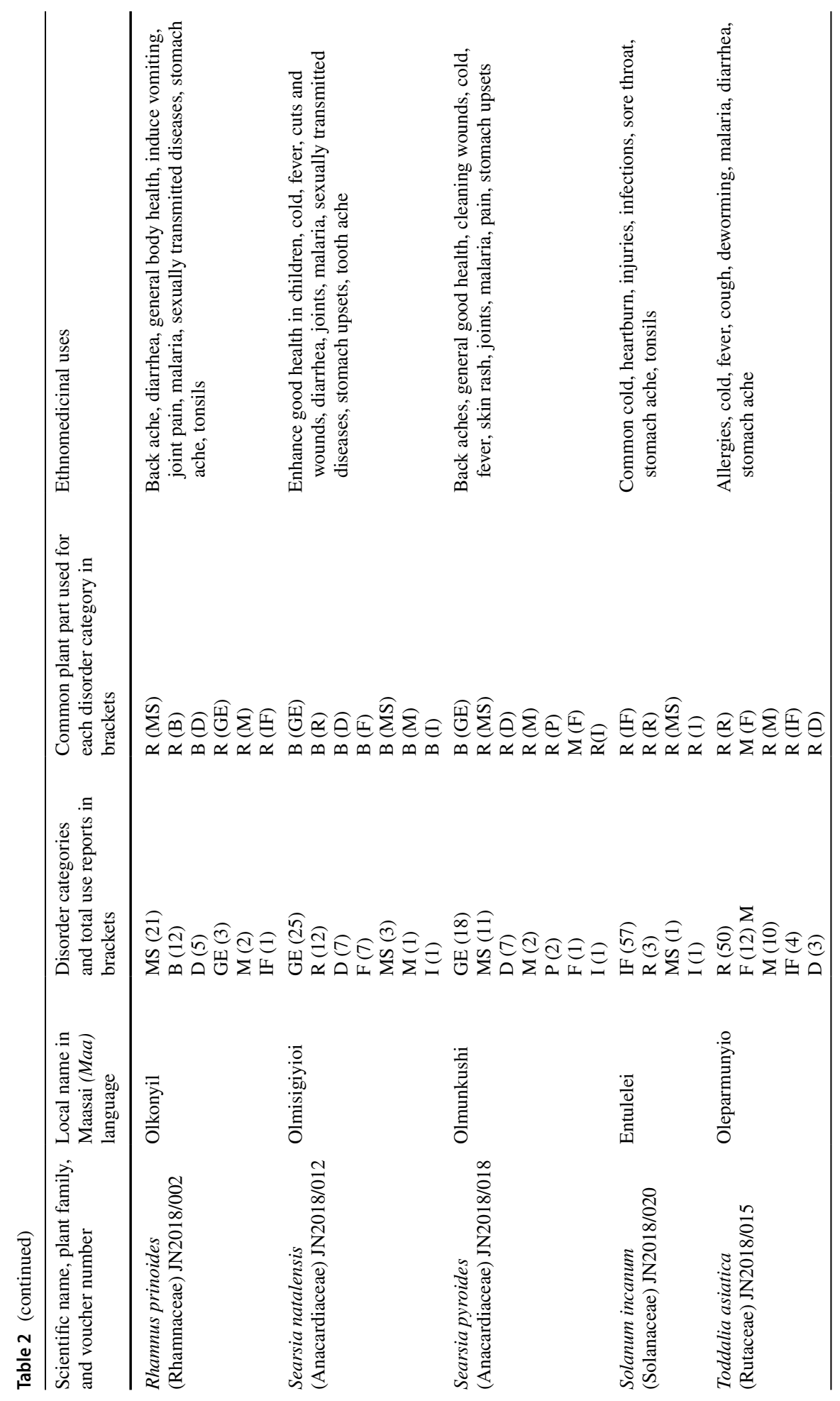




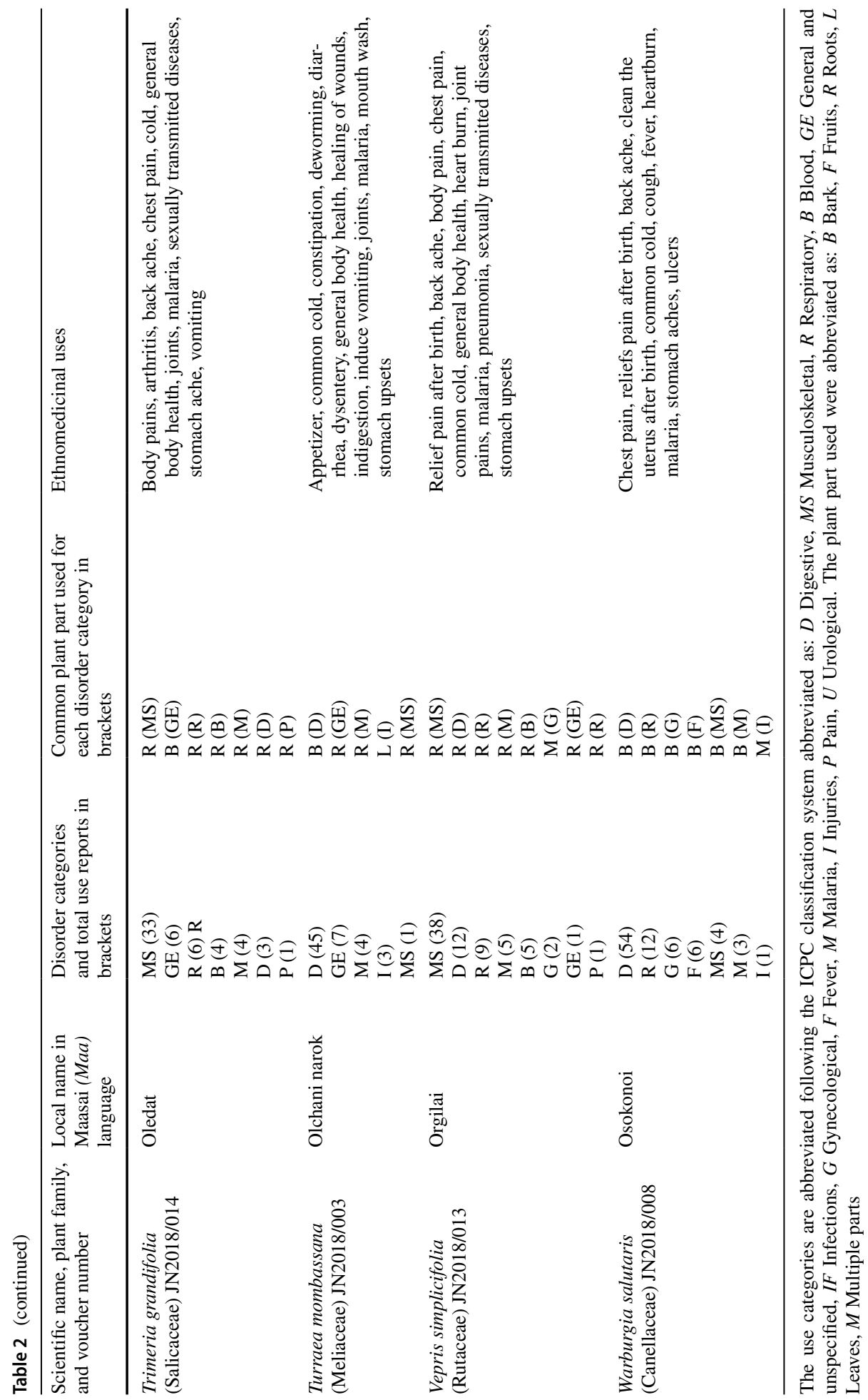


Table 3 Conservation priority list of medicinal plant species used by the Loita Maasai in Entasekera, Kenya, based on versatility, plant part harvested, and availability

\begin{tabular}{|c|c|c|c|c|}
\hline Species & $\begin{array}{l}\text { Versatility (ail- } \\
\text { ments/score) }\end{array}$ & Part used/score & Availability/score & Sum \\
\hline Myrsine africana & $16 / 4$ & Roots/4 & Abundant/1 & 9 \\
\hline Turraea mombassana & $15 / 3$ & Roots/4 & Abundant/1 & 8 \\
\hline Gymnosporia heterophylla & $12 / 3$ & Roots/4 & Abundant/1 & 8 \\
\hline Vepris simplicifolia & $12 / 3$ & Roots/4 & Abundant/1 & 8 \\
\hline Dovyalis abyssinica & $11 / 3$ & Roots/4 & Abundant/1 & 8 \\
\hline Trimeria grandifolia & $11 / 3$ & Roots/4 & Abundant/1 & 8 \\
\hline Searsia pyroides & $10 / 3$ & Roots/4 & Abundant/1 & 8 \\
\hline Acacia kirkii & $9 / 2$ & Roots/4 & Abundant/1 & 7 \\
\hline Carissa spinarum & $9 / 2$ & Roots/4 & Abundant/1 & 7 \\
\hline Rhamnus prinoides & $9 / 2$ & Roots/4 & Abundant/1 & 7 \\
\hline Toddalia asiatica & $8 / 2$ & Roots/4 & Abundant/1 & 7 \\
\hline Solanum incanum & $7 / 2$ & Roots/4 & Abundant/1 & 7 \\
\hline Acacia nilotica & $14 / 3$ & Bark/2 & Abundant/1 & 6 \\
\hline Olea europaea & $12 / 3$ & Bark/2 & Abundant/1 & 6 \\
\hline Acacia sieberiana & $11 / 3$ & Bark/2 & Abundant/1 & 6 \\
\hline Warburgia salutaris & $11 / 3$ & Bark/2 & Abundant/1 & 6 \\
\hline Searsia natalensis & $10 / 3$ & Bark/2 & Abundant/1 & 6 \\
\hline Lippia javanica & $13 / 3$ & Leaves/1 & Abundant/1 & 5 \\
\hline Olinia usambarensis & $8 / 2$ & Bark/2 & Abundant/1 & 5 \\
\hline Prunus africana & $6 / 2$ & Bark/2 & Abundant/1 & 5 \\
\hline
\end{tabular}

\section{Musculoskeletal disorders}

Muscular disorders had second highest number $(240,20 \%)$ of use reports. The most commonly reported illnesses in this category were backache and joint pain. $12(63 \%)$ out of the 19 species, listed as being used in this category, were classified under the high conservation priority with summed scores of seven or above in the prioritization.

\section{Respiratory disorders}

In this category, 17 species were used in treatment. Toddalia asiatica, which is classified as having high conservation priority, was the most used species for treatment, with $50(25 \%)$ of the total use reports in this category. The most often mentioned illnesses listed under this category were common cold and chest pain. 


\section{Blood disorders}

Blood disorders contributed $99(8 \%)$ of the total use reports, with 12 species reported to be used in treatment. The roots were the most frequently harvested plant part, and Carissa spinarum was the most commonly used species for treatment.

\section{General and unspecified disorders}

This category contributed $92(8 \%)$ of the total use reports. Illnesses which are not precisely defined, such as good health and body strength, were classified under this category. Thirteen species were reported to be used with Searsia natalensis and Searsia pyroides being the most preferred species for treatment. The bark and roots were the most widely used plant parts for medication of these illnesses.

\section{Infections}

Infections were reported to be treated using ten species contributing $74(6 \%)$ of the total use reports. The main illnesses classified under this category were sore throat and tonsils. These illnesses were mostly treated using the roots of Solanum incanum.

\section{Gynecological disorders}

$45 \%$ of all species and $62(5 \%)$ of all use reports related to women's medicine. The widely used species were Acacia kirkii and Acacia sieberiana, which were used by women to expel the placenta after birth and to reduce pain during delivery.

\section{Fever}

Illnesses in this category were treated with ten species, with Toddalia asiatica, Olinia usambarensis, and Olea europaea reported to be widely preferred plants. The bark was the most common plant part used for treatment.

\section{Malaria}

$80 \%$ (16) of all the species are employed against malaria. Olea europaea and Toddalia asiatica were the commonly used species for treatment. The most frequently harvested plant parts were the roots and the bark. 


\section{Injuries}

In this category, $40 \%$ (8) of the species were used for treatment. Cuts and wounds were the common complaints in this category. The frequently used species for treatment were Turraea mombassana and Acacia nilotica.

\section{Pain}

This category had the second lowest proportion $(6,0.5 \%)$ of all the use reports and $25 \%$ of all the species. Searsia pyroides was the most widely used species for treatment, with roots reported to be the most preferred plant part for treatment.

\section{Urological disorders}

This category had the lowest number $(1,5 \%)$ of the species used for medication and had the fewest $(1,0.08 \%)$ use reports. Urological complaints reported were; pain while urinating and urinary tract issues. Multiple plant parts were used for treatment. Interestingly, Myrsine africana which had the highest total score of nine, and classified under high conservation priority, was the only species reported to be used for treatment of illness classified in this category.

\section{Discussion}

The Maasai heavily depend on medicinal plants for their wellbeing, a practice that is entrenched in their culture. The Loita Maasai collect medicinal plants from the wild in the nearby forest and they do not cultivate them (Nankaya et al. 2019). The community use local conservation strategies to protect their natural resources meaning they largely practice in-situ conservation. In our results, Myrsine africana was used to treat 16 different illnesses and had the highest score. Indicating that it should be given conservation priority. A similar study carried out in southeastern Ethiopia, to determine threats to medicinal plants evaluated the degree of threats and rarity of the commonly used medicinal plants, and reported Withania somnifera as the most threatened species (Lulekal et al. 2008). Use of single plants for treating multiple conditions was also reported in a study conducted in Peru, which found that all species had multiple uses (Phillips and Gentry 1993). The multiple uses of medicinal plants for treatment may be attributed to their ease of availability (Lucena et al. 2007). The high number of uses reported for Myrsine africana could be attributed to ease of availability in the study area or it could be because it is effective in treatment. The species should therefore be given the highest conservation priority for sustainability.

Of all the species listed, Prunus africana was the least used and it had the fewest use reports. The few use reports could mean that only a few people in the study area know the species and its uses and therefore it is not much used for medication.

Based on the three prioritization criteria, a total of 12 plant species were categorized as having high conservation priority, and eight were classified as having second priority. In all the 12 species the roots were the preferred plant part for treatment. These findings agree with some other ethnobotanical studies (Kimondo et al. 2015; Muthee et al. 2011; Yineger et al. 2008) which reported the use of roots to be the most preferred plant part for 
medication. The high usage of roots compared with other parts of the plant is thought to be a result of high concentrations of bioactive chemical compounds (Srithi et al. 2009). The preference of the roots for extraction of medicine by the Loita Maasai could be due to the fact that the roots can be stored for a long time after harvesting, making it possible to stock medicine for use when needed instead of having to go out and collect it every time. From a conservation perspective, harvesting of roots compared with harvesting other parts of the plant, is not sustainable and can be very destructive and lead to reduced or depleted populations (Kimondo et al. 2015). In addition, a majority of the species used as medicine in Loita are trees; which may take a long time to regenerate. As a result, daily consumption and over-reliance on these species may lead to depletion. Since the harvesting of roots may not be sustainable, propagation and establishment of seedbanks (ex situ conservation) may be one measure to counteract depletion.

Our informants reported that all the 20 most commonly used species were abundant around the village and easily available, which could be the reason for the multiple uses of the species. In the past, the Maasai moved from one place to another in search of fresh pasture and water for their livestock. The movement ensured that they did not deplete the available resources which enabled the species to regenerate. However, in the recent past the Loita Maasai have adopted a semi-permanent settlement as agro-pastoralists which implies that their dependence on the medicinal plants found around the village may increase considerably.

\section{Use categories}

Digestive system disorder was the most common disorder affecting the Loita Maasai. Diarrhea, a common illness reported in this category, could be attributed to poor sanitation practices. During field work, we noticed that there were very few toilets and some households did not have bathrooms. Members of households without toilets defecate in the nearby bushes, leading to contamination of water sources, especially during the rainy season.

Stomach ache and constipation may be attributed to the eating habits of the Maasai which involves a diet of mainly meat and milk. High consumption of meat may either lead to constipation or flatulence. The traditional practice of consuming un-boiled milk may also cause stomach ache and upsets. Worm infestation may increase due to consumption of uncooked or semi-cooked meat parts such as the kidney and liver all of which may lead to digestive system imbalance.

Our results agree with the findings of a study on African palms (Gruca et al. 2015) and Ethnobotany of the Loita Maasai (Maundu et al. 2001), both of which reported gastrointestinal disorders also known as digestive system disorders to be prevalent.

The second most common ailment category was muscular skeletal disorders. The joints and muscle aches reported under this category could be associated with the difficult terrain in the study area. Men walk for long distances in search of fresh pastures and water for their livestock while women trek far away from the village in search of water for domestic use, firewood, and house construction materials. The strenuous activities they engage in could cause muscle aches and joint pains.

Medicinal plants used in the treatment of digestive system, muscular skeletal and respiratory system disorders should be prioritized for conservation due to their high demand. The illnesses classified in the categories of pain, injuries and urological disorders had the 
least use reports, and few species were used for treatments, maybe because the species were becoming rare in the village, and may require special knowledge to be found.

\section{Conclusion and way forward}

The reliance on medicinal plants by the Loita Maasai is evident with over 200 illnesses reported justifying the urgent need for medicinal plant conservation. $60 \%$ of the medicinal species most commonly used were classified under high conservation priority. All 20 species had more than one use indicating the need to monitor the diversity of medicinal plants for wellbeing of the people.

To ensure sustainability of the heavily relied upon medicinal plants, there is an urgent need for more research to determine the population status of the plants classified as having high conservation priority. Conservation measures for the 12 species should be initiated to protect them from overexploitation. One such measure would be to use conventional methods to cultivate medicinal plants around the village and in home-gardens (ex situ conservation). Cultivation of medicinal species may reduce the pressure on the wild resources.

Our study highlights the medicinal plants that should be given conservation priority for human and ecosystem health, but it is in no way complete. Area specific population assessment of medicinal species using standard ecological methods is highly recommended.

Acknowledgements We thank all the informants for sharing their knowledge with us.

Author contributions JN, NG, CL and HB conceived the study. JN prepared the manuscript, NG, CL and $\mathrm{HB}$ reviewed and edited the manuscript and approved the final version.

Funding The work was financed entirely by the authors.

\section{Compliance with ethical standards}

Conflict of interest The authors have no conflict of interest to declare that are relevant to the content of this article.

Ethical approval Permission to carry out this study was obtained from the Kenya National Commission for Science, Technology and Innovation (Permit Number NACOSTI/18/54615/26671). The permit was obtained through the Maasai Mara Science Development Initiative. We also received permission to collect data from the area chief. The informants were made aware of the purpose of the study, and we obtained verbal consent from each participant.

Informed consent The informants were made aware of the purpose of the study, and we obtained verbal consent from each participant.

Open Access This article is licensed under a Creative Commons Attribution 4.0 International License, which permits use, sharing, adaptation, distribution and reproduction in any medium or format, as long as you give appropriate credit to the original author(s) and the source, provide a link to the Creative Commons licence, and indicate if changes were made. The images or other third party material in this article are included in the article's Creative Commons licence, unless indicated otherwise in a credit line to the material. If material is not included in the article's Creative Commons licence and your intended use is not permitted by statutory regulation or exceeds the permitted use, you will need to obtain permission directly from the copyright holder. To view a copy of this licence, visit http://creativecommons.org/licenses/by/4.0/. 


\section{References}

Anyinam C (1995) Ecology and ethnomedicine: exploring links between current environmental crisis and indigenous medical practices. Soc Sci Med 40:321-329

Berkes F, Colding J, Folke C (2000) Rediscovery of traditional ecological knowledge as adaptive management. Ecol Appl 10(5):1251-1262

Chi et al (2017) Threatened medicinal plants in China: distributions and conservation priorities. Biol Cons 210:89-95

Cook FEM (1995) Economic botany data collection standard. Royal Botanic Gardens, Kew, London

Dhar U, Rawal RS, Upreti J (2000) Setting priorities for conservation of medicinal plants-a case study in the Indian Himalaya. Bio Conserv 95:57-65

Etkin NL (1998) Indigenous patterns of conserving biodiversity: pharmacologic implications. J Ethnopharmacol 63:233-245

Figueiredo MSL, Grelle CEV (2009) Predicting global abundance of a threatened species from its occurrence: implications for conservation planning. Divers Distrib 15:117-121

Franz C (1993) Domestication of wild growing medicinal plants. Plant Res Dev 37:101-111

Galaty J (1982) Being "Maasai"; Being "People-of-Cattle": ethnic shifters in East Africa. Am Anthropol 9(1): $1-20$

Ghimire SK, Mckey D, Aumeeruddy-Thomas Y (2005) Conservation of Himalayan medicinal plants: harvesting patterns and ecology of two threatened species, Nardostachys grandifora and Neopicrorhiza scrophulariifora. Biol Cons 124:463-475

Giday M, Asfaw Z, Elmqvist T, Woldu Z (2003) An ethnobotanical study of medicinal plants used by the Zay people in Ethiopia. J Ethnopharmacol 85:43-52

Gruca M, Blach-Overgaard A, Balslev H (2015) African palm ethno-medicine. J Ethnopharmacol 165:227-237

Gupta A, Vats SK, Lal B (1998) How cheap can a medicinal plant species be? Curr Sci 74:555-556

Hamilton AC (2004) Medicinal plants, conservation and livelihoods. Biodivers Conserv 13:1477-1517

Huang H, Han X, Kang L, Raven P, Jackson PW, Chen Y (2002) Conserving native plants in China. Science 297:935-936

Hughes L (2006) Moving the Maasai: a colonial misadventure. Palgrave Macmillan, Basingstoke, New York

Huntington HP (2000) Using traditional ecological knowledge in science: methods and applications. Ecol Appl 10(5):270-1274

Kala CP, Farooquee NA, Dhar U (2004) Prioritization of medicinal plants on the basis of available knowledge, existing practices and use value status in Uttaranchal, India. Biodivers Conserv 13:453-469

Kimondo J, Miaron J, Mutai P, Njogu P (2015) Ethnobotanical survey of food and medicinal plants of the Ilkisonko Maasai community in Kenya. J Ethnopharmacol 175:463-469

Kunwar RM, Acharya RP, Chowdhary CL, Bussmann RW (2015) Medicinal plant dynamics in indigenous medicines in far west Nepal. J Ethnopharmacol 163:210-219

Lucena RF, Araujo E, Albuquerque UP (2007) Does the local availability of woody caatinga plants (Northeastern Brazil) explain their use value? Econ Bot 61(4):347-361

Lulekal E, Kelbessa E, Bekele T, Yineger H (2008) An ethnobotanical study of medicinal plants in Mana Angetu District, southeastern Ethiopia. J Ethnobiol Ethnomed 4:10

Mackinson S, Nottestad L (1998) Points of view: Combining local and scientific knowledge. Rev Fish Biol Fish 8(4):481-490

Martin GJ (2010) Ethnobotany: a methods manual. Chapman and Hall, London

Maundu P, Berger D, Ole Saitabau C, Nasieku J, Kipelian M, Mathenge S, Morimoto Y, Höft R (2001) Ethnobotany of the Loita Maasai: Towards community management of the forest of the lost child. Experiences from the Loita ethnobotany project. People and Plants Working Paper, vol 8. UNESCO, Paris, pp 1-34

McCabe JT, Perkins S, Schofield C (1992) Can conservation and development be coupled among pastoral people? An examination of the Maasai of the Ngorogoro Conservation Area, Tanzania. Hum Org 51(4):353-366

Miaron JO (2003) The Maasai ethnodiagnostic skill of livestock diseases: a lead to traditional bioprospecting. J Ethnopharmacol 84(1):79-83

Millenium Ecosystem Assessment (MEA) (2005) Ecosystem and human wellbeing synthesis Millenum Ecosytem Assessment. Island Press, Washington, D.C.

Muchiru AN, Western D, Reid RS (2009) The impact of abandoned pastoral settlements on plant and nutrient succession in an African savanna ecosystem. J Arid Environ 73:322-331 
Muthee JK, Gakuya DW, Mbaria JM, Kareru PG, Mulei CM, Njonge FK (2011) Ethnobotanical study of anthelmintic and other medicinal plants traditionally used in Loitoktok district of Kenya. J Ethnopharmacol 135:15-21

Nankaya J, Nampushi J, Petenya S, Balslev H (2019) Ethnomedicinal plants of the Loita Maasai of Kenya. J Environ Dev Sustain 22(3):2569-2589

Okello MM (2005) Land use changes and human-wildlife conflicts in the Amboseli Area, Kenya. Hum Dimens Wildl Int J 10(1):19-28

Padulosi S, Leaman D, Quek P (2002) Challenges and opportunities in enhancing the conservation and use of medicinal and aromatic plants. J Herbs, Spices Med Plants 9(4):243-267

Phillips O, Gentry A (1993) The useful plants of Tambopata, Peru: I Statistical hypotheses tests with a new quantitative technique. Econ Bot 47(1):15-32

Pyke GH (1984) Optimal foraging theory: a critical review. Annu Rev Ecol Syst 15:523-575

Rausser GC, Small AA (2000) Valuing Research Leads: Bioprospecting and the Conservation of Genetic Resources. UC Berkeley Law and Economics Working Paper No. 00-11

Seno SK, Shaw WW (2002) Land tenure policies, Maasai traditions, and wildlife conservation in Kenya. Soc Nat Resour 15:79-88

Singh MP, Dey S (2005) Indian medicinal plants. Satish serial Publishing House, Delhi

Soldati GT, de Albuquerque UP (2012) A New application for the optimal foraging theory: The extraction of medicinal plants. Evid-Based Complement Altern Med 1:364564

Srithi K, Balslev H, Wangpakapattanawong P, Srisanga P, Trisonthi C (2009) Medicinal plant knowledge and its erosion among the Mien (Yao) in northern Thailand. J Ethnopharmacol 123(2):335-342

Staub PO, Geck SM, Weckerle CS, Casu L, Leonti M (2015) Classifying diseases and remedies in ethnomedicine and ethnopharmacology. J Ethnopharmacol 174:514-519

The Plant List (2013) Version 1.1. http://www.theplantlist.org/. Accessed 25 May 2019

Vieira RF (1999) Conservation of medicinal and aromatic plants in Brazil. In: Janick J (ed) Perspectives on new crops and new uses. ASHS Press, Alexandria, pp 152-159

Voeks RA, Leony A (2004) Forgetting the forest: assessing medicinal plant erosion in Eastern Brazil. Econ Bot 58(1):S294-S306

WHO (1987) International Classification of Primary Care, Second edition (ICPC-2) http://www.who.int/ classifications/icd/adaptations/icpc2/en/. Accessed 22 May 2019

WHO (2017) International Classification of Diseases (ICD) Information sheet http://www.who.int/classifica tions/icd/factsheet/en/. Accessed 22 May 2019

WONCA (2005) International Classification Committee (WICC) http://www.kith.no/upload/2705/icpc-2english.pdf.Accessed 21 May 2019

World Health Organization (WHO) (2002) Traditional medicine-growing needs and potential. WHO Policy Perspectives Med 2:1-6

Yineger H, Yewhalaw D, Teketay D (2008) Ethnomedicinal plant knowledge and practice of the Oromo ethnic group in southwestern Ethiopia. J Ethnobiol Ethnomed 4(1):11

Zemede A (2001) The role of home gardens in production and conservation of medicinal plants. In: Zewdu M, Demissie A (eds) Proceedings of the National Workshop on Biodiversity Conservation and Sustainable Use of Medicinal Plants in Ethiopia. IBCR, Addis Ababa, pp 76-91

Publisher's Note Springer Nature remains neutral with regard to jurisdictional claims in published maps and institutional affiliations.

\title{
Authors and Affiliations
}

\author{
Jedidah Nankaya ${ }^{1,2} \cdot$ Nathan Gichuki $^{1} \cdot$ Catherine Lukhoba ${ }^{1} \cdot$ Henrik Balslev $^{3}$ (D \\ Jedidah Nankaya \\ nankaya@mmarau.ac.ke \\ Nathan Gichuki \\ ngichuki@uonbi.ac.ke \\ Catherine Lukhoba \\ clukhoba@uonbi.ac.ke
}


1 School of Biological Sciences, University of Nairobi, P.O. Box 30197-00100, Nairobi, Kenya

2 School of Natural Resource and Animal Sciences, Maasai Mara University, P.O Box 861-20500, Narok, Kenya

3 Department of Bioscience-Ecoinformatics and Biodiversity, Aarhus University, Build. 1540, Ny Munkegade 116, 8000 Aarhus C, Denmark 